\title{
The impact of gasoline price changes on traffic safety: a time geography explanation
}

\author{
Guangqing Chi ${ }^{\mathrm{a}, *}$, Jeremy R. Porter ${ }^{\mathrm{b}}$, Arthur G. Cosby ${ }^{\mathrm{c}, 1}$, David Levinson ${ }^{\mathrm{d}, 2}$ \\ ${ }^{a}$ Department of Sociology and Social Science Research Center, Mississippi State University, PO Box C, Mississippi State, MS 39762, United States \\ ${ }^{\mathrm{b}}$ Graduate Center, Brooklyn College and Institute for Demographic Research, City University of New York, 218 Whitehead Hall, 2900 Bedford Avenue, New York, \\ NY 11210, United States \\ ${ }^{c}$ Social Science Research Center, Mississippi State University, PO Box 5287, Mississippi State, MS 39762, United States \\ ${ }^{\mathrm{d}}$ Department of Civil Engineering, University of Minnesota, 500 Pillsbury Drive SE, Minneapolis, MN 55455, United States
}

\section{A R T I C L E I N F O}

\section{Keywords:}

Time geography

Gasoline prices

Traffic safety

Traffic crashes

Fatal crashes

Space-time path

\begin{abstract}
A B S T R A C T
The impact of gasoline price changes on traffic safety has received increasing attention in empirical studies. In this study, we use time geography to provide a theoretical framework for examining the effects of time-varying fluctuations in gasoline prices and their relationship to traffic safety in a case study of Mississippi from April 2004 to December 2010. Application of time geography theory suggests that gasoline prices act as one type of capability constraint of the space-time path. As gasoline prices increase (that is, as the capability constraint becomes stronger), we hypothesize traffic crash rates decrease, and they decrease more for groups for whom the constraint is stronger. The results corroborate the hypotheses and suggest that gasoline prices have stronger effects on reducing less severe crashes and negligible effects on reducing fatal crashes. Gasoline price effects on reducing crashes start at a 9-month lag, peak at a 12-month lag, and diminish after an 18-month lag.
\end{abstract}

(c) 2012 Elsevier Ltd. All rights reserved.

\section{Introduction}

Recent gyrations in gasoline prices have resulted in complex social and spatial implications for travelers, the public, planners, and decision makers. In response to gasoline price increases, travelers may reduce gasoline consumption by reducing driving frequency and distance, shifting from personal vehicles to public transport, driving in a more fuel-efficient manner (such as driving more slowly and reducing sudden speeding and braking), switching to fuel-efficient vehicles, and relocating closer to workplaces (Graham and Glaister, 2004; Goodwin et al., 2004). These changes in commuting behaviors and residential location could eventually lead to improved traffic safety (in terms of lower levels of crash frequency and rates). Although a large body of the literature has empirically examined the impact of gasoline price changes on traffic safety (see Chi et al., 2010, for a review of the literature), the impact has not yet been explained from a conceptual or theoretical perspective. This study helps fill this gap in the literature by exploring the impact through the conceptual framework of time geography theory (Hägerstrand, 1970).

\footnotetext{
* Corresponding author. Tel.: +1 662325 7872; fax: +1 6623257966 .

E-mail addresses: gchi@ssrc.msstate.edu (G. Chi), jporter@brooklyn.cuny.edu (J.R. Porter), arthur.cosby@ssrc.msstate.edu (A.G. Cosby), dlevinson@umn.edu (D. Levinson).

1 Tel: +1 662325 7127; fax: +1 6623257966 .

2 Tel.: +1 612625 6354; fax: +1 6126267750 .
}

Time geography theory has been used to study various perspectives of transportation accessibility, such as bus services (Lenntorp, 1976), commute modes and times (Burns, 1979), accessibility modeling with geographic information systems (Miller, 1991), disparities in gender accessibility (Kwan, 1998), and spatial-temporal characteristics of individuals in the age of instant access (Yu and Shaw, 2007). It has also proven to be an important organizing principle for modeling travel behavior as a set of linked activities and travel decisions subject to constraints on resources such as time (Kitamura and Fujii, 1996). We assert that the theory of time geography can also be useful for explaining the effects of gasoline price changes on traffic safety. Within the theoretical framework of time geography, we understand gasoline prices as one type of capability constraint. We expect that as gasoline prices increase (as the capability constraint becomes stronger), traffic crash frequency and rates will decrease. Furthermore, we expect that this capability constraint will be stronger for some drivers (those with lower incomes or weaker claims on household incomes) and will manifest itself in differential effects by age, gender, and race. Time geography provides the theoretical underpinnings for predictions of the effects of gasoline prices on traffic safety by producing testable hypotheses that the empirical analysis corroborates.

It should be noted that in this study, time geography is used as a theoretical and analytical framework but not as the direct mechanism for the analysis. This is due to two reasons. One, data that cover both individual commuting behaviors and traffic crashes are unavailable to sustain such an analysis. Time geography 
analysis requires detailed individual travel records over a period of time. Such data are expensive to collect and thus the data samples are often very small to generate representative crash records, which tend to be infrequent. Likewise, the traffic crash data that are available do not provide the detailed travel records of the drivers involved in the crashes. Two, even when appropriate data become available, the use of time geography for an analysis has to deal with the mismatch of the levels for analysis: research on traffic crashes are often conducted at aggregate levels, but time geography studies are mostly conducted at the individual level. While this issue could be solved by multi-level models or other advanced methods, this would require substantial methodological advances. Therefore, time geography is used as the conceptual framework to explain the link from higher gasoline prices to less driving and less aggressive driving to reduce traffic crash frequency and rates.

The next section summarizes existing studies of gasoline price effects on traffic safety. Immediately following, Section 3 reviews time geography theory and proposes a conceptual framework for understanding the relationship between gasoline prices and traffic crashes within that context. Next, Section 4 introduces the data that are related to traffic crashes and fatal crashes by age, gender, and race in the state of Mississippi from April 2004 to December 2010 and addresses the methods that direct our analyses. Section 5 reports our findings and tests the hypotheses produced by time geography theory. Section 6 summarizes our findings and discusses the linkage of time geography to the empirical analysis of gasoline prices and traffic safety in future research.

\section{Prior research of gasoline price effects on traffic safety}

An increasing body of the literature examines gasoline price effects on traffic safety (see Chi et al., 2010, for a review of the literature). Most of the studies, which have focused largely on fatal crashes (e.g., Grabowski and Morrisey, 2004; Leigh and Geraghty, 2008; Leigh and Wilkinson, 1991; Wilson et al., 2009), found that increasing gasoline prices (or taxes) lead to greater traffic safety as measured by fewer traffic crashes. The effects were found to vary by demographic characteristics of drivers and by crash types. These findings highlight a couple of important trends that have helped guide the current research.

First, existing literature on the subject has consistently shown that the effects of gasoline prices on traffic crashes differ by age, gender, and race. The effects tend to be stronger on younger drivers than on older drivers, on female drivers than on male drivers, and on white drivers than on black drivers (Chi et al., 2010, 2012; Grabowski and Morrisey, 2004; Leigh and Wilkinson, 1991). Second, gasoline prices affect different types of traffic crashes such as fatal crashes, injury crashes, property-damage-only crashes, and drunk-driving crashes differently (Chi et al., 2011; Huang and Levinson, 2010). When compared to the effects on overall crashes, gasoline prices are found to have more significant effects on less severe crashes but less significant effects on drunkdriving crashes.

Although the existing studies have found a statistically significant association between gasoline prices and traffic crashes, a conceptual or theoretical framework has not been given to explain their association. In this study, we use time geography theory to explain that the effect of gasoline prices on traffic crashes occurs through reduced travel and changed driving behavior. It is not that higher gasoline prices themselves lead to higher traffic safety. Rather, it is that higher gasoline prices discourage driving and change driving behaviors (e.g., reducing fuel consuming speed or drunk driving), which in turn lead to higher traffic safety.

\section{Understanding gasoline price effects on traffic safety within time geography theory}

\subsection{Time geography theory}

Originally developed by Hägerstrand (1970), time geography theory studies the relationships between the behavioral possibilities of individuals and the various spatial and temporal constraints on those behaviors (Shaw and Yu, 2009; Yu and Shaw, 2007). The core notion of time geography is that an individual's existence and activities are constrained by spatial and temporal attributes (Pred, 1977) - an individual can only participate in activities in a single location in space at one single time (Miller, 1991; Miller and Bridwell, 2009). Three types of constraints on an individual's activities exist: capability constraints, authority constraints, and coupling constraints (Hägerstrand, 1970). Capability constraints refer to biological (e.g., sleeping and eating) and physical (e.g., vehicle ownership, time availability, maximum speed of travel, ability to afford) limitations that restrict an individual from participating in activities. Authority constraints represent limitations to accessing particular areas (e.g., military bases) or individuals that are classified by certain people or institutions. Coupling constraints indicate limitations for two or more individuals to participate in an activity in the same location at the same time interval. These three types of constraints dictate the spatial and temporal patterns of an individual's movements. Cullen and Godson (1975) further refined the notion of constraints by noting that temporal constraints might vary in their rigidity by time of day, with constraints weakening later in the day as more discretionary activities are pursued.

Within this approach, an individual's movements in space over time generate a space-time path, which can be understood as a series of lines in a three-dimensional system in which space is represented by a two-dimensional plane and time is represented by the vertical axis. However, any space-time path represents only one of many possible space-time paths that can be taken by an individual in a given time interval. All the points that an individual can reach, from an origin location to a destination location, at a given time interval comprise a space-time prism. The prism is determined by the intermediate locations between the origin and destination points, the time required for participation in activities at those locations, and the travel time between each point. The space-time path and space-time prism are the two most essential concepts of time geography, and they provide a valuable measure of an individual's accessibility within particular spatial and temporal constraints (Miller, 1991).

\subsection{Conceptual framework}

We understand gasoline prices as one type of capability constraint. Higher gasoline prices reduce the amount of gasoline an individual can afford to consume, causing an individual to drive less distance, less frequently, or perhaps less aggressively, in turn reducing exposure to traffic crashes. Gasoline price increases reduce transportation accessibility by reducing the lengths and frequencies of economically feasible space-time paths, ${ }^{3}$ which in turn leads to fewer traffic crashes. However, the capability constraint of gasoline prices varies by income and private vehicle ownership. An individual with higher income tends to have a higher capability of gasoline consumption and is less vulnerable to gasoline price increases. Yet the income influence on the gasoline price constraint is conditional on private vehicle ownership - gasoline prices affect automobile usage only if an individual owns a private vehicle. For

\footnotetext{
${ }^{3}$ When gasoline prices increase, the space-time prism may not change at all over a short term, as a prism is calculated on the basis of fixed activities.
} 
those who own private vehicles but have low income, the effect is substantial. For those who do not own private vehicles, gasoline price changes are less likely to affect driving. For example, blacks and Latinos, who have relatively lower private vehicle ownership rates (Raphael and Stoll, 2001), are less likely to be affected by gasoline price increases. In contrast, young drivers, who have the worst traffic safety record collectively, and own cars but lack discretionary income, are likely to be substantially affected by increases in gasoline prices.

We conceptualize gasoline prices as influencing traffic safety through at least five intermediate factors: trip frequency and distance for work and especially non-work trips, commute modes, driving behaviors (e.g., reducing fuel consuming speed or drunk driving), vehicle fuel efficiency, and residential and work locations (Fig. 1). First, rising gasoline prices could cause people to drive shorter distances by reducing trip frequency (fewer space-time paths) and distance (shorter space-time paths) as well as to make more multi-purpose (linked or chained) trips rather than singlepurpose trips (for shorter total lengths of space-time paths) (Huang and Levinson, 2010). Commuters may adjust work schedules to travel to work fewer days per week. Higher fuel prices may also have macro-economic effects that result in reduced overall employment (Goodwin et al., 2004). Second, an increase in gasoline prices could cause some drivers to switch from personal vehicle use to other commuting modes, such as public transportation (Lane, 2010), carpooling, biking, or walking (fewer motor vehicle space-time paths and fewer destinations reached by motor vehicle). Third, surging gasoline prices could cause people to drive in a more fuel-efficient manner such as driving more slowly and reducing sudden speeding and braking (Goodwin et al., 2004), which in turn likely lowers crash risk. These three paths through which gasoline prices affect traffic safety likely occur immediately after gasoline price increases. The effects may be non-linear, as they affect different groups differently. For instance because relatively risk-seeking young drivers are more likely to be priced out of the market (Chi et al., 2010), the remaining drivers on average will be more risk-averse and safer.

Fourth, over the long term, an increase in gasoline prices could persuade some drivers to switch to fuel-efficient vehicles (Goodwin et al., 2004), which are equipped with better safety technologies. However, fuel-efficient vehicles are generally lighter and thus are more vulnerable if hit by a larger vehicle but are likely to cause less damage to another vehicle or a pedestrian in a crash. Therefore, gasoline price increases might reduce total crashes but might increase more severe crashes through the fuel-efficient vehicle intermediator. Nevertheless, the net effects of lightness and safety have been found to be insignificant (Leigh and Wilkinson, 1991). Fifth, over the long term, increased gasoline prices could also induce workers, especially low- and medium-income automobile commuters who live far from their workplaces, to relocate closer to their workplaces (shorter space-time paths) and may encourage low-wage, younger, and part-time workers to find jobs nearer their residences (shorter space-time paths) (Graham and Glaister, 2004). This may also have secondary effects of increasing or decreasing trip frequency and distance for non-work trips.

These conceptual links through which gasoline prices affect traffic safety are complex. They have not been tested in existing studies; this study likewise does not attempt to directly test these conceptual links. Measurement of the intermediate links might have potentially large errors, and the conceptual links might be imprecise. Moreover, the data for studying these conceptual links are unavailable and may be difficult to collect. Therefore, instead of modeling the effects by these links, this research directly models the hypothesized implications of the links, i.e., the effects of gasoline prices on reducing traffic crashes. The conceptual links are used to introduce the framework through which we interpret our findings and highlight the underlying mechanisms that drive the findings reviewed in the literature review section.

That said, time geography provides predictions of gasoline price effects on traffic safety through the intermediate factors. Rising gasoline prices reduce the total lengths of an individual's motor-vehicle-based space-time paths during a given time interval - i.e., an individual travels less and for shorter distances by car - which in turn reduces the likelihood of a traffic crash for that individual. Rising gasoline prices also reduce the aggregate driving aggressiveness by differentially affecting younger risk-seeking drivers more than older risk-averse drivers. Thus the average individual is safer. Therefore, we expect that as gasoline prices increase (as the capability constraint becomes stronger) both traffic crash frequency and rates will decrease. It should be noted that the effects of gasoline prices on the total lengths, crash frequency, and crash rates vary along the space-time paths and across the space-time prisms. For example, work trips cannot be easily reduced (though people can switch, e.g., to 4-day or 4/5-day work schedules) but non-mandatory trips can be reduced; crash rates vary by the time of a day; and travel by public transportation is safer than travel by personal vehicles. All the heterogeneity attributes to the variation of gasoline price effects on crash frequency and rates.

As we expect capability constraints to be differentially impactful, we expect that significant variations will exist across demographic categorizations of the population. We expect that gasoline price effects are stronger on (1) the traffic crash rate of younger drivers, who have greater capability constraints due to their lower incomes (Chi et al., 2010); (2) the traffic crash rate of women, who have greater elasticity in the nature of their trips

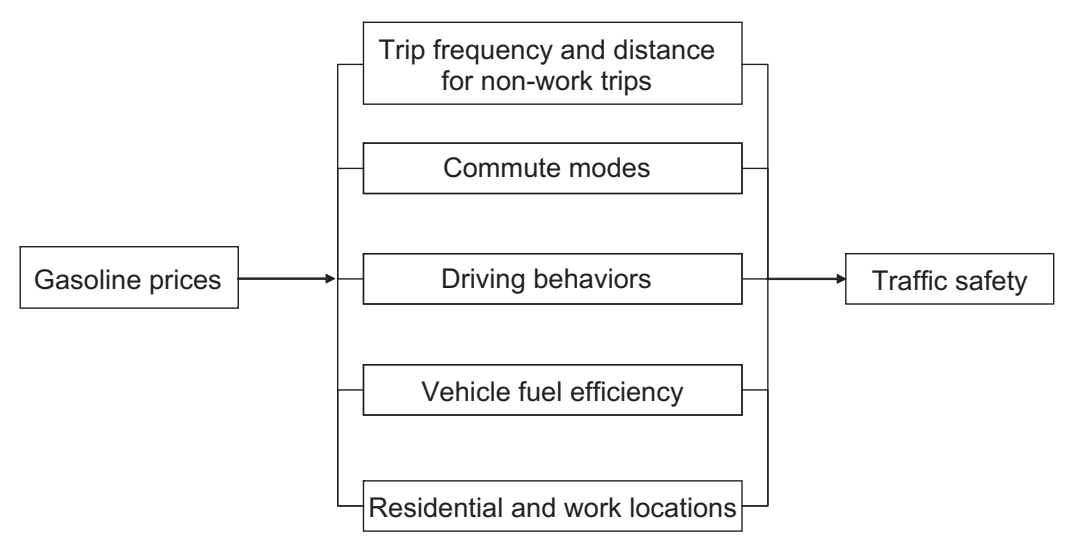

Fig. 1. A conceptual framework. 
due to the larger number of non-work trips that are not time and space fixed (Ren and Kwan, 2009); and (3) the traffic crash rate of whites, who have greater rates of ownership of private vehicles, greater travel distances by private vehicles (Raphael and Stoll, 2001), and more discretionary trips by auto to give up.

\section{Data and methods}

\subsection{Data and variables}

This study makes use of data provided by the Mississippi Highway Patrol and analyzes monthly traffic crashes (both total crashes and fatal crashes) in the state of Mississippi from April 2004 until December 2010. Following the recent work of Chi et al. (2010), this analysis is unique in that most studies to date have only examined the effects of gasoline prices on traffic fatalities (e.g., Grabowski and Morrisey, 2004; Leigh and Wilkinson, 1991; Wilson et al., 2009) by making use of Fatal Accident Reporting System (FARS) data, which report fatal accidents only. Our data provide information on vehicles, drivers, and passengers of all traffic accidents documented by the Mississippi Highway Patrol during the identified period. In Mississippi, the only crashes that are not mandated to be reported are property-damage-only crashes with property losses less than $\$ 500$; all other crashes are required to be reported regardless of the property loss involved. Both fatal and nonfatal crashes are counted on the basis of the drivers, not the passengers. If an accident involves two drivers, it is counted as two crashes; if one of the two drivers died, this accident would be counted as one fatal crash and two total crashes. The data are aggregated to the state at the monthly level. The summary statistics of crashes are presented in Table 1.

Data for monthly regular-grade gasoline prices in Mississippi are obtained from the Energy Information Administration of the US Department of Energy (Fig. 2). Gasoline prices are adjusted for inflation in January 2011 dollars. This study also controls for other factors that may affect traffic crashes, such as seat belt usage (Evan and Graham, 1991), alcohol sales (Chi et al., 2011), state unemployment rate (Graham and Glaister, 2003), precipitation (Quddus, 2008), and temperature. Seat belt usage is measured as the percentage of drivers who wear seat belts while driving; the data were collected annually in 409 observation points from 2004 to 2007 and in 168 observation points from 2008 to 2010 by the Mississippi Department of Public Safety (2010). Alcohol sales are measured as the annual sales of beer, wine, and spirit per capita in gallons in Mississippi; the data source is the Beer Institute (2011). The monthly unemployment rate in Mississippi is provided by the US Bureau of Labor Statistics (2011). Data for the monthly

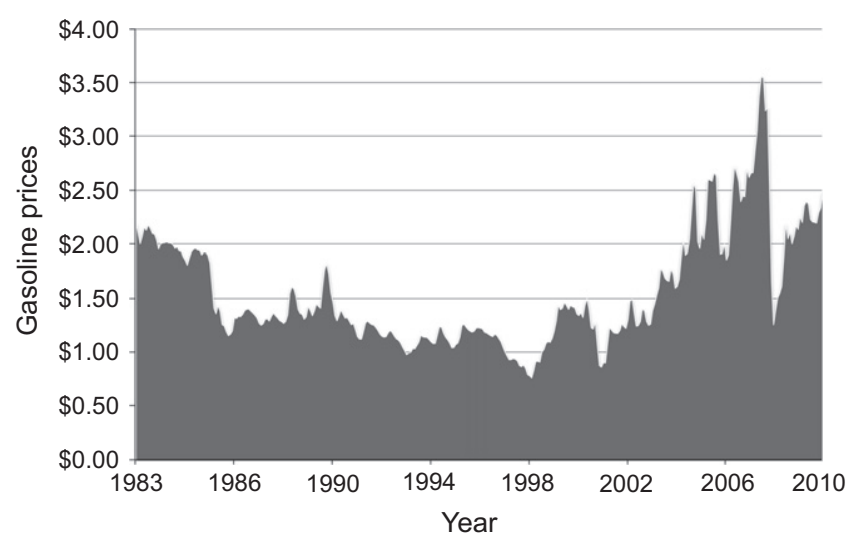

Fig. 2. Monthly average gasoline prices (in January 2011 dollars) in Mississippi, 1983-2010. Data source: Energy Information Agency, US Department of Energy (2012).

average precipitation and temperature in Mississippi are obtained from the Southeast Regional Climate Center (2012).

\subsection{Methods}

Existing studies suggest that the effects of gasoline prices on traffic crashes may occur both over the short and long terms (Chi et al., 2010; Dahl and Sterner, 1991; Grabowski and Morrisey, 2004). These studies mostly use arbitrary gasoline price measures, including gasoline prices at the current time, a 1-year lag, a 2-year lag, a 3-year lag, and/or a 4-year lag, without strong justifications. However, the inclusion of 3- and 4-year lag gasoline prices could be problematic, as gasoline prices change frequently and gasoline price effects on traffic crashes more likely occur in the short rather than long term. Gasoline prices at shorter intervals over a short term may provide more reasonable measures. Nevertheless, when the effects occur and how long the effects last have never been investigated in the existing literature. In this study, we first examine the temporal relationship between gasoline prices and traffic crashes by illustrating the correlation between monthly-lagged gasoline prices and crashes (Fig. 3).

Fig. 3 tests the correlation of prices by month intervals and shows that the Pearson's correlation between gasoline prices and crashes is neither strong nor statistically significant prior to a 9month lag at the $p \leqslant 0.05$ level. That is, the correlation between gasoline prices and crashes is negligible at the current time, a 1-month lag, a 2-month lag, ... and an 8-month lag. All the

Table 1

Descriptive statistics of crashes at the monthly level in Mississippi, April 2004-December 2010.

\begin{tabular}{|c|c|c|c|c|c|c|c|c|}
\hline & \multicolumn{4}{|l|}{ Total crashes } & \multicolumn{4}{|l|}{ Fatal crashes } \\
\hline & Monthly mean & Std. dev. ${ }^{a}$ & Minimum & Maximum & Monthly mean & Std. dev. & Minimum & Maximum \\
\hline \multicolumn{9}{|c|}{ Driver characteristics } \\
\hline \multicolumn{9}{|c|}{ Age } \\
\hline $15-23$ & 2485 & 342 & 1360 & 3105 & 17 & 7 & 3 & 37 \\
\hline $24+$ & 7471 & 775 & 4679 & 9303 & 62 & 14 & 29 & 96 \\
\hline \multicolumn{9}{|l|}{ Gender } \\
\hline Male & 5244 & 639 & 3085 & 6784 & 58 & 14 & 25 & 105 \\
\hline Female & 4712 & 478 & 2950 & 5589 & 21 & 6 & 7 & 38 \\
\hline \multicolumn{9}{|c|}{ Race/ethnicity } \\
\hline White & 6490 & 733 & 3970 & 8056 & 45 & 12 & 15 & 76 \\
\hline Black & 3466 & 361 & 2076 & 4201 & 24 & 7 & 7 & 44 \\
\hline Total & 9956 & 1076 & 6115 & 12,257 & 79 & 18 & 36 & 127 \\
\hline
\end{tabular}

\footnotetext{
a Std. dev. = standard deviation.
} 


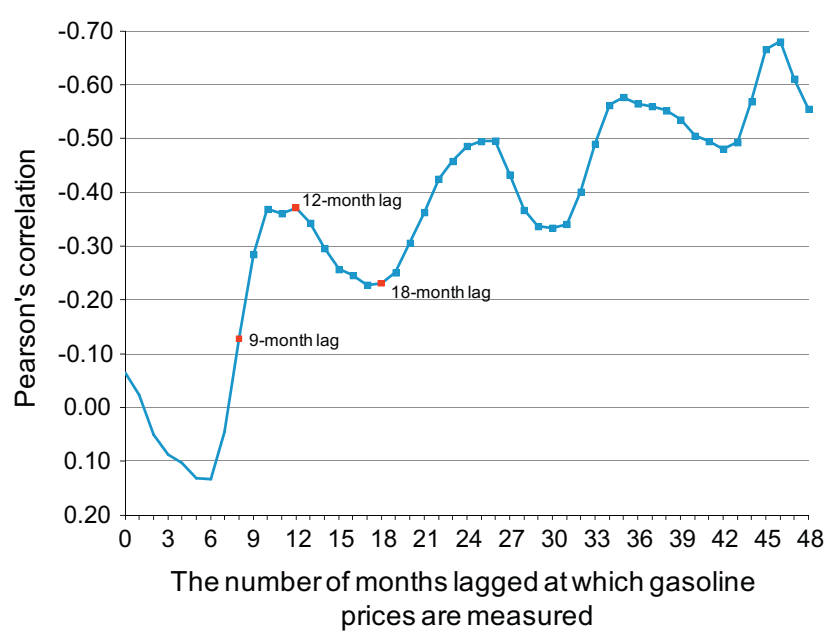

Fig. 3. Pearson's correlation between monthly total crashes and monthly-lagged gasoline prices in Mississippi, April 2004-December 2010. Note: all the correlations at a 9-month lag and later are statistically significant at the $p \leqslant 0.05$ level; all the correlations prior to a 9-month lag are not significant.

correlations at a 9-month lag and later are statistically significant. For example, March 2010 is the first month whose gasoline prices have an effect on crashes that occurred in December 2010. The correlation peaks at a 12-month lag and bottoms at an 18-month lag. After that, the correlation follows a general uptrend with seasonal variations. However, we suspect that gasoline price effects on traffic crashes are limited to an 18-month period and that the higher correlation after the 18-month period might be the result of a coincidence of secular changes and seasonal variation in gasoline prices and crashes. The secular changes are that traffic safety is improving over the long term, while prices are increasing over this period. Our suspicion is supported by the findings of existing studies in which gasoline prices at 3-year and 4-year lags do not have statistically significant effects on traffic crashes (e.g., Chi et al., 2010). However, the threshold of the time lag needs to be further investigated in future research. Here we identify the reasonable time lags at which gasoline prices are associated with traffic crashes for the purpose of including appropriate gasoline price variables in regression models. We use four gasoline price measures in the analysis: gasoline prices at the current time, a 9-month lag, a 12-month lag, and an 18-month lag. For instance, corresponding to traffic crashes in December 2010, the concurrent gasoline price is measured as of December 2010, the gasoline price at a 9-month lag is measured as of March 2010, the gasoline price at a 12-month lag is measured as of December 2009, and the gasoline price at an 18-month lag is measured as of June 2009.

We then use the gasoline price measures to examine their relationship with traffic crashes as well as crashes by age (15-23 and $24+$ years old), gender (male and female), and race (white and black $)^{4}$ at the monthly level. We also examine the effects on fatal crashes for comparison purposes. In total, there are 14 crash measures: 7 for all crashes and 7 for fatal crashes. Our analysis shows that all 14 crash measures exhibit overdispersion, suggesting that negative binomial regression is more appropriate than Poisson regression for modeling the data (Long, 1997). Therefore, negative binomial regression models are used for all crash measures. Each model is a function of gasoline prices at the current time, a 9-month lag, a 12-month lag, and an 18-month lag, seat belt usage, state unemployment rate, alcohol sales, precipitation, and temperature.

\footnotetext{
${ }^{4}$ Crashes of Latino drivers are not examined in this study as Latinos make up a very small proportion of the Mississippi population - only $2.7 \%$ of the population was of Hispanic origin in 2010 (US Bureau of Census, 2011)
}

Along with the explanatory variables, a continuous time trend variable (i.e., April $2004=1$, May $2004=2$, ..., December $2010=81$ ) is included in all models to control for the effect of time on crashes. ${ }^{5}$ In addition, total population (age $15+$ ) as well as populations of young (age 15-23), adult (age $24+$ ), male, female, white, and black are used as exposure variables ${ }^{6}$ in corresponding models. Thus, the models actually examine the effect of gasoline prices on crash rates (the number of crashes per capita) rather than on crash counts.

\section{Results}

\subsection{Gasoline prices and total crashes}

Fig. 4 presents the association between quarterly ${ }^{7}$ average gasoline prices at the current time, a 9-month lag, a 12-month lag, and an 18-month lag (all adjusted for inflation) and traffic crashes in Mississippi from April 2004 to December 2010. Quarterly averages are used in the figure only to reduce the fluctuations in gasoline prices and crashes so that clearer associations between them can be illustrated; the statistical analysis is conducted at the monthly level. The average gasoline prices (in cents) are labeled on the left $y$ axis and traffic crashes per 1000 persons are labeled on the right $y$-axis. The overall trend of the relationship shows that traffic crash rates fall as average gasoline prices rise. This is particularly evident in some specific periods across the figure. Among the four gasoline price variables, gasoline prices at a 12-month lag seem to have the strongest association with crashes per 1000 persons, which is also supported by Fig. 5. For example, from quarter 4 (Q4) of 2005 to Q3 of 2006, the crash rate decreased constantly while gasoline prices at a 12-month lag increased constantly. This pattern happened again from Q4 of 2007 to Q2 of 2008 and from Q4 of 2008 to Q2 of 2009. When gasoline prices at a 12-month had the steepest decline, from Q3 to Q4 of 2009, the crash rate had a rapid increase. The fatal crash rate, however, does not have a strong association with any of the four gasoline price variables (Fig. 5).

The effects of gasoline prices on the total traffic crash rate and the fatal crash rate are then examined at the monthly level using negative binomial regression models (Appendices $A$ and $B$, respectively). To facilitate the interpretation, elasticities of crashes per capita with respect to gasoline prices are calculated at the mean price of $\$ 2.22$ (for the studied period) and presented in Table 2 for the significant (at the $p \leqslant 0.10$ level) gasoline price variables. It was found that gasoline price at the current time does not have significant effects on reducing total crashes. The three lagged gasoline prices do have significant effects on reducing total crashes. A $1 \%$ increase in the inflation-adjusted gasoline price at a 9-month lag is associated with a $0.10 \%$ decrease in the monthly total crash rates. Gasoline price at a 12-month lag has stronger effects on reducing crashes - a $1 \%$ increase in the gasoline price is associated with a $0.16 \%$ decrease in the monthly total crashes per capita. In addition, a $1 \%$ increase in gasoline price at an 18-month lag is associated with a $0.12 \%$ decrease in the monthly total crash rates. However, none of the four gasoline price variables have statistically

\footnotetext{
${ }^{5}$ Future research could benefit from formal tests of the possible temporal autocorrelation in model residuals, more advanced time-series analysis models, and finer model specifications.

${ }^{6}$ Alternatively, vehicle miles travelled (VMT) and the number of vehicles on the road could be used as exposure variables. However, data for VMT by age, gender, and race are not available in Mississippi. Also, data for the number of vehicles on the road would be very difficult (if available) to obtain in Mississippi. Population can be appropriately used as an exposure variable, as it is often used as the denominator in calculating a rate of interest in public health studies (e.g., mortality due to a certain disease; e.g., Horner et al., 2009).

7 Quarterly data relate to standard calendar year quarters such that Q1 represents data from January to March, Q2 represents data from April to June, Q3 represents data from July to September, and Q4 represents data from October to December.
} 


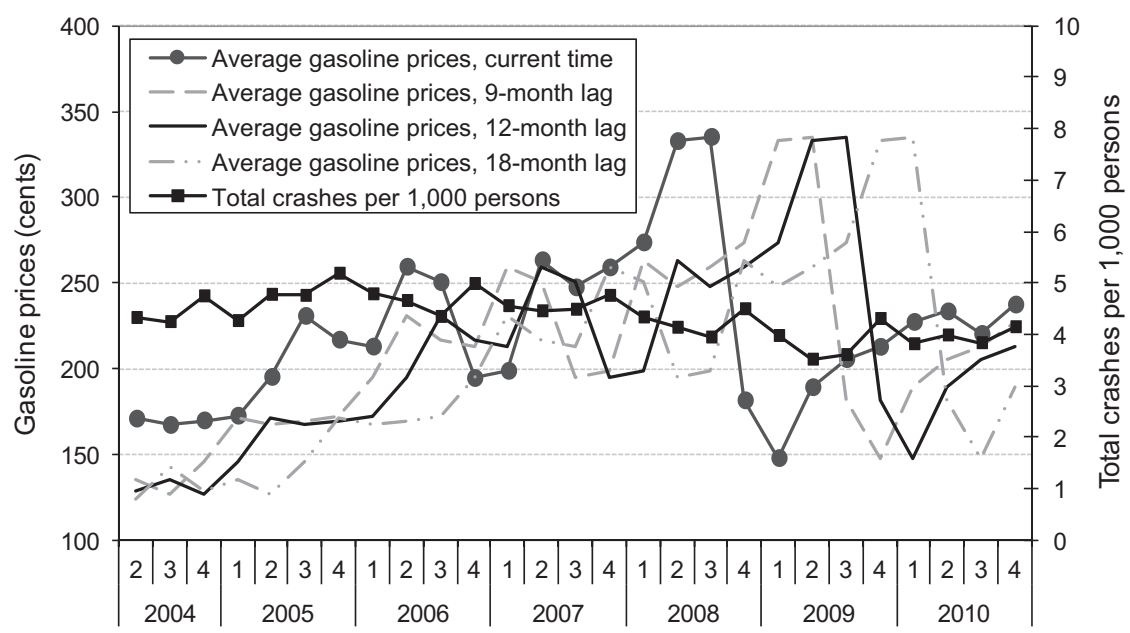

Fig. 4. Average gasoline prices and total traffic crashes per 1000 capita by quarter in Mississippi, 2004-2010.

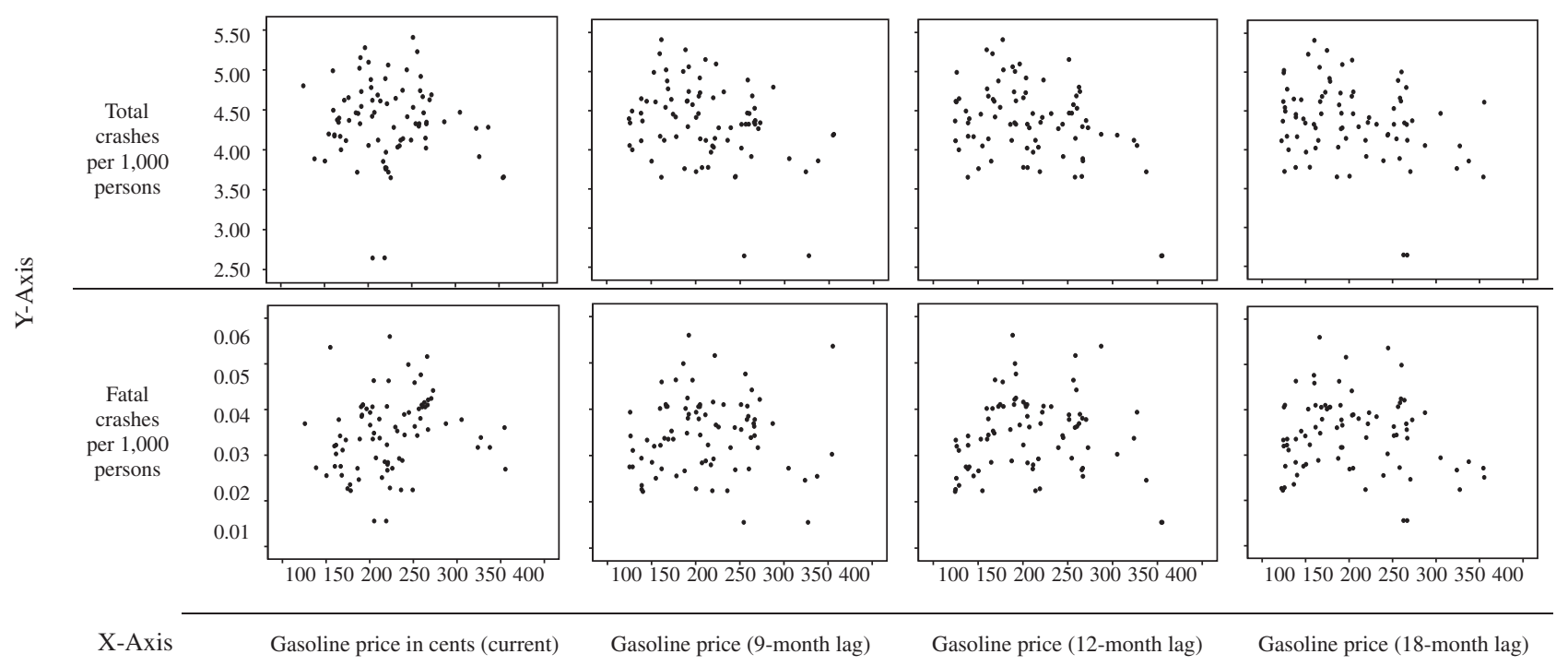

Fig. 5. Scatterplots of total crashes and fatal crashes by monthly gasoline prices in Mississippi, April 2004-December 2010.

Table 2

Elasticities of crashes per capita with respect to gasoline prices estimated from negative binomial regression models, Mississippi, April 2004-December 2010.

\begin{tabular}{|c|c|c|c|c|c|c|c|}
\hline & \multirow[t]{2}{*}{ Total } & \multicolumn{2}{|l|}{ Age } & \multicolumn{2}{|l|}{ Gender } & \multicolumn{2}{|l|}{ Race } \\
\hline & & $15-23$ Years & $24+$ years & Men & Women & White & Black \\
\hline \multicolumn{8}{|l|}{ Total crashes } \\
\hline Gasoline price at the current time & & -0.1428 & & & & & \\
\hline Gasoline price at a 9-month lag & -0.1025 & -0.1229 & -0.0944 & -0.0954 & -0.1114 & -0.1106 & \\
\hline Gasoline price at a 12-month lag & -0.1563 & & -0.1655 & -0.1930 & & -0.1599 & -0.1488 \\
\hline Gasoline price at a 18 -month lag & -0.1232 & & -0.1333 & -0.1476 & & -0.1267 & -0.1171 \\
\hline \multicolumn{8}{|l|}{ Fatal crashes } \\
\hline Gasoline price at the current time & & & & & & & -0.3260 \\
\hline \multicolumn{8}{|l|}{ Gasoline price at a 9-month lag } \\
\hline Gasoline price at a 12 -month lag & & & & & -0.5897 & -0.2020 & \\
\hline Gasoline price at a 18 -month lag & & & & & & & \\
\hline
\end{tabular}

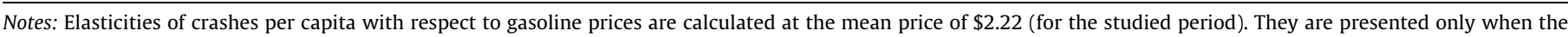
corresponding gasoline price variables are statistically significant at the $p \leqslant 0.10$ level.

significant effects on reducing fatal crashes. This finding is consistent with that from Chi et al. (2011), who found gasoline prices have stronger effects on less severe crashes but weaker effects on more severe crashes.
As discussed in the section on the theoretical framework of time geography, gasoline prices can be understood as one type of capability constraint. Higher gasoline prices reduce the affordability of gasoline for middle- and low-income drivers. The total lengths and 
frequencies of their space-time paths are likely reduced, which could in turn decrease the probability of their involvement in traffic crashes.

Previous traffic safety studies suggest that driving behaviors vary among the younger and the older populations, men and women, and whites and blacks, which in turn could produce different traffic safety outcomes among these groups (van den Bossche et al., 2007). Thus, we further divided the crash data by age, gender, and race to analyze gasoline price effects on the total traffic crash rates and fatal crash rates of each of these groups.

\subsection{Variations by age}

The younger population (15-23 years old) accounts for $25 \%$ of the total crashes while the older population ( $24+$ years old) accounts for $75 \%$ of the total crashes; the percentages are similar for corresponding fatal crashes (Table 1). To examine variations of gasoline price effects on crashes by age, we ran negative binomial regression models for the crash rates of the younger and older populations separately at the monthly level. As shown in Table 2, it was found that the gasoline price has more immediate effects on the traffic crash rate among the younger population: a $1 \%$ increase in the inflation-adjusted gasoline price is associated with a $0.14 \%$ decrease in monthly crashes per capita immediately and a $0.12 \%$ decrease at a 9-month lag. Gasoline prices do not have significant effects on the crash rate at a 12-month lag and an 18-month lag. The younger population tends to have lower income than the older population and thus is more vulnerable to gasoline price increases. In other words, the capability constraint of gasoline prices more strongly affects the younger population. Therefore, one would expect that when gasoline prices increase, the younger population is likely unable to consume as much gasoline as previously. Thus, the frequency and total lengths of their space-time paths tend to be reduced immediately, which in turn reduces their exposure to traffic crashes.

For the older population, gasoline prices do not have an immediate effect, but an intermediate-term effect on the crash rate of the older people was demonstrated. A $1 \%$ increase in the inflation-adjusted gasoline price is associated with a 0.09\% decrease in monthly crashes per capita of the older people at a 9-month lag, a $0.17 \%$ decrease at a 12 -month lag, and a $0.13 \%$ decrease at an 18-month lag. The older population may have more work and household responsibilities (more coupling constraints) that limit their willingness to reduce trips immediately. Partly because of their greater responsibilities, the older population may react to gasoline price changes more conservatively; the older population is more experienced in dealing with gasoline price changes. In addition, they have relatively higher incomes than the younger population, and thus their capability constraint imposed by gasoline prices is weaker. Gasoline prices have no significant effects on fatal crash rates of the younger or the older populations. This finding is again consistent with that from the Chi et al. (2011) study that found no gasoline price effects on fatal crashes.

\subsection{Variations by gender}

Prior research indicates that travel behaviors differ between men and women (Ren and Kwan, 2009). Thus, it is possible that gasoline prices may have different effects on traffic safety between men and women. To test this hypothesis, we ran negative binomial regression models for the crash rates of men and women separately at the monthly level. Male drivers account for $53 \%$ of the total crashes while female drivers account for $47 \%$ of the total crashes; the percentages are $73 \%$ and $27 \%$ for fatal crashes, respectively. The results in Table 2 indicate that gasoline prices have no significant effects on the fatal crash rate of male drivers but a significant effect on the fatal crash rate of female drivers at a 12 month lag. Gasoline prices have an intermediate-term effect on the traffic crash rate of men, very similar to the findings on the crash rate of the older population. A $1 \%$ increase in the inflation-adjusted gasoline price is associated with a $0.10 \%$ decrease in monthly crashes per capita of male drivers at a 9-month lag, a $0.19 \%$ decrease at a 12 -month lag, and a $0.15 \%$ decrease at an 18 month lag. Gasoline price does not have an immediate effect on the crash rate of male drivers. A larger proportion of men's trips are work related (Meyer, 2006); because work-related trips are less easily changed, the number and frequency of men's trips are much less immediately affected by gasoline price changes. Thus, men's space-time paths are less vulnerable to gasoline price changes in the short term.

The effect that gasoline prices have on reducing women's crash rate is limited to a 9-month lag: a $1 \%$ increase in the inflation-adjusted gasoline price is associated with a $0.11 \%$ decrease in women's monthly total crashes per capita. That gasoline prices have a more immediate effect on the crash rates of women than those of men may be due to gender differences. Women have different preferences, values, and concerns regarding traffic safety and are more sensitive to traffic safety than men (Woodcock et al., 2001). In Mississippi, women are likely to be responsible for more household activities, such as grocery shopping, taking children to school or other activities, and taking other adults to medical appointments. Accordingly, they make more frequent short-distance trips. In response to gasoline price increases, women could change frequent short-distance trips to less frequent multi-purpose trips. Although women do make more linked or chained trips than men (McGuckin and Nakamoto, 2006), women could make further adjustments to make more multi-purpose trips. This may explain why women's space-time paths might be reduced in response to gasoline price increases.

\subsection{Variations by race}

White drivers account for $65 \%$ of total crashes while black drivers account for $35 \%$; the percentages are $58 \%$ and $42 \%$ for fatal crashes, respectively. To analyze variations of gasoline price effects on crashes by race, we ran negative binomial regression models for the crash rates of white and black drivers separately at the monthly level. The effects that gasoline prices have on reducing the crash rate of white drivers are similar to those of the older population. A $1 \%$ increase in the inflation-adjusted gasoline price is associated with a $0.11 \%$ decrease in whites' monthly total crashes per capita at a 9 -month lag, a $0.16 \%$ decrease at a 12 -month lag, and a $0.13 \%$ decrease at an 18 -month lag. Whites have relatively higher private vehicle ownership rates (Raphael and Stoll, 2001) and more discretionary trips by auto to give up; thus they are more exposed to the impact of gasoline price changes. When gasoline prices increase, whites who own vehicles but have low incomes might change their commuting behaviors by any of the mechanisms described in the previous section.

For blacks, gasoline prices only have effects on reducing the crash rate at a 12 -month lag and an 18-month lag. A $1 \%$ increase in the inflation-adjusted gasoline price is associated with a $0.15 \%$ decrease in blacks' monthly total crashes per capita at a 12-month lag and a $0.12 \%$ decrease at an 18 -month lag. However, gasoline price effects on reducing crashes of whites and blacks are similar according to the results. This is puzzling, as whites and blacks have different levels of income and personal vehicle ownership. There are two possible reasons. One is that Mississippi is a very rural state and largely lacks public transportation. The other is that for those living in Jackson and the Gulf Coast, where public transportation is available, the use of public transportation is mostly for work trips that are fixed in terms of route lengths and times. 
Therefore, gasoline prices do not have differential effects on crashes involving white drivers and black drivers in Mississippi. ${ }^{8}$ In terms of fatal crashes, gasoline prices have an effect on reducing the fatal crash rate of white drivers at a 12-month lag and of black drivers immediately. Overall, gasoline prices have much weaker effects on fatal crashes than on total crashes, for which a majority of them are nonfatal crashes.

\section{Summary and discussion}

The impact of gasoline price changes on traffic safety has been increasingly addressed in empirical studies. However, the impact has not been explained from a conceptual or theoretical perspective. In this study, we use time geography theory to understand the effects of gasoline prices on traffic safety by age, gender, and race in a case study of Mississippi at the monthly level from April 2004-December 2010. We argue that higher gasoline prices discourage driving and in particular reduce driving in the risk-seeking younger population, which in turn leads to higher traffic safety. The results show that gasoline prices have stronger effects on reducing less severe crashes and negligible effects on reducing fatal crashes at the monthly level. It was found that a $1 \%$ increase in gasoline prices is associated with a $0.10 \%$ decrease in monthly total crashes per capita at a 9-month lag, a $0.16 \%$ decrease at a 12 month lag, and a $0.12 \%$ decrease at an 18 -month lag. The effects that gasoline prices have on reducing crashes of the younger population occur immediately, but the effects on reducing crashes of the older population occur over an intermediate term. The effects on reducing crashes of male drivers occur over a longer term than those of female drivers. The effects on reducing crashes of whites and blacks are similar. The results also suggest that gasoline price effects on reducing crashes start at a 9-month lag, peak at a 12month lag, and diminish after an 18-month lag.

The findings can be explained within the framework of time geography theory. Gasoline prices can be seen as a capability constraint of the space-time path. Gasoline price increases differentially reduce gasoline affordability and thus consumption. Reduction of gasoline consumption is concomitant with reduction of vehicle travel. Therefore, drivers who are more vulnerable to gasoline price increases are more likely to reduce their space-time path lengths. These ends might be achieved through a number of means: reducing the number of trips, converting frequent shortdistance trips to multi-purpose trips, switching from private vehicles to public transportation, driving in a more fuel-efficient manner, using more fuel-efficient vehicles, and relocating to be closer to valued destinations (such as workplaces). The first three mechanisms are likely to occur in the short term, while the latter two take longer. However, the implementation of these mechanisms tends to differ by age, gender, and race. The younger population typically has greater capability constraints due to lower incomes, and thus their crash rates likely decrease as gasoline prices increase. Women typically conduct more household activities and make more short-distance trips than men; women drivers could therefore adjust to multi-purpose trips in response to gasoline price increases, which reduces their space-time path lengths and frequencies. This study did not find substantial variations in the effects by race, likely due to the lack of public transportation in

\footnotetext{
8 This would likely be different for large metropolitan areas where public transportation is convenient. In such areas, gasoline price changes tend to have less effect on the commuting modes of blacks than on those of whites. Blacks are more likely to live in central city neighborhoods, which provide easier access to public transportation (Deka, 2004; Massey and Denton, 1993). When gasoline prices are low, blacks depend on public transportation because they have low private vehicle ownership rates; when gasoline prices are high, they still depend on public transportation.
}

Mississippi. In large metropolitan areas where convenient public transportation systems are available, we expect variations in the effects by race because of differential private vehicle ownership; whites are more likely to own one or more private vehicles, and because of their greater travel by private vehicle, rising gasoline prices more sharply reduce their space-time path lengths through the various means of travel adjustment.

In conclusion, these findings highlight a complex relationship between temporal shifts in gasoline prices and their unique effects on traffic crashes that is further tempered by the availability of resources across specific demographic groups. Thus, we expect systematic variations in space-time paths that are directly related to the unique conditions experienced at the intersections of age, gender, and race. In this sense, time geography provides a framework in which we can conceptualize the potential impact of shifts in gasoline prices on traffic crashes and their relationship to groupspecific adjustments to space-time paths. This study contributes to the literature on gasoline prices and traffic safety and the application of time geography theory in three ways. First, based on a dataset that covers a longer time period with both economic growth and decline, the results confirm that higher gasoline prices lead to higher levels of traffic safety. Two, this study investigates the time intervals by which gasoline prices are associated with traffic crashes, which has not been addressed in previous research of gasoline prices and crashes. Three, this study applies time geography to explain gasoline price effects on traffic safety; prior research has not provided theoretical explanations for the effects.

The relationship between gasoline prices and traffic safety could be further investigated in at least four research directions. First, the capability constraint argument of the time geography theory should be empirically tested. In this study, time geography is used only as an explanatory framework and is not linked directly and disaggregately to the empirical results of gasoline price effects on traffic safety. This not only represents a limitation of this research but also provides opportunities for future research. Although the results show that rising gasoline prices generally lead to a reduction in traffic crashes, the linkages from gasoline prices to individual space-time paths and from individual space-time paths to specific traffic crashes are not tested in this study, as large longitudinal individual travel behavior data samples were unavailable; yet this might be addressed in future research when combined with network analysis of individual travel. Potential datasets for addressing this issue include individual travel records collected by wireless carriers, individual travels tracked by GPS, Twitter user records when personal location information is disclosed, and others.

Second, how gasoline prices and traffic safety are associated temporally should be comprehensively investigated. Most previous studies use yearly-lagged gasoline prices for studying traffic safety without strong justifications. It seems more reasonable that the effects occur at much shorter intervals. In this study, we conducted a preliminary analysis of the temporal association between gasoline prices and traffic safety. Future research should investigate this comprehensively by demographic groups, crash types, and regions.

Third, future research could benefit from spatial regression analysis when data at the county level become available in Mississippi or from conducting the analysis in other states where gasoline price data below the state level are available. Many studies have found that crashes exhibit spatial variation (e.g., Quddus, 2008). Gasoline prices also vary locally. Models incorporating spatial dependence and/or heterogeneity might provide insights into the spatial variation of gasoline price effects on crashes. This would also help control for local variations of other variables such as unemployment.

Fourth, it might be promising to study the variation of gasoline price effects on traffic safety by socioeconomic groups. The affordability of gasoline and personal vehicles is more of a socioeconomic issue (Goodwin et al., 2004). Thus, gasoline price effects on traffic 
Negative binomial regression models for total crashes per capita in Mississippi, April 2004-December 2010.

\begin{tabular}{|c|c|c|c|c|c|c|c|}
\hline & \multirow[t]{2}{*}{ Total } & \multicolumn{2}{|l|}{ Age } & \multicolumn{2}{|l|}{ Gender } & \multicolumn{2}{|l|}{ Race } \\
\hline & & $15-23$ years & $24+$ years & Men & Women & White & Black \\
\hline Gasoline price at the current time & $\begin{array}{l}-0.0004 \\
(0.0003)\end{array}$ & $\begin{array}{l}-0.0006^{\dagger} \\
(0.0003)\end{array}$ & $\begin{array}{l}-0.0003 \\
(0.0003)\end{array}$ & $\begin{array}{l}-0.0004 \\
(0.0003)\end{array}$ & $\begin{array}{l}-0.0004 \\
(0.0003)\end{array}$ & $\begin{array}{l}-0.0004 \\
(0.0003)\end{array}$ & $\begin{array}{l}-0.0003 \\
(0.0003)\end{array}$ \\
\hline Gasoline price at a 9-month lag & $\begin{array}{l}-0.0007^{\dagger} \\
(0.0003)\end{array}$ & $\begin{array}{l}-0.0006^{\dagger} \\
(0.0003)\end{array}$ & $\begin{array}{l}-0.0004^{\dagger} \\
(0.0003)\end{array}$ & $\begin{array}{l}-0.0004^{\dagger} \\
(0.0003)\end{array}$ & $\begin{array}{l}-0.0005^{\dagger} \\
(0.0003)\end{array}$ & $\begin{array}{l}-0.0005^{\dagger} \\
(0.0003)\end{array}$ & $\begin{array}{l}-0.0004 \\
(0.0003)\end{array}$ \\
\hline Gasoline price at a 12 -month lag & $\begin{array}{l}-0.0007^{*} \\
(0.0003)\end{array}$ & $\begin{array}{l}-0.0006 \\
(0.0004)\end{array}$ & $\begin{array}{l}-0.0007^{*} \\
(0.0003)\end{array}$ & $\begin{array}{l}-0.0009^{* *} \\
(0.0003)\end{array}$ & $\begin{array}{l}-0.0005 \\
(0.0003)\end{array}$ & $\begin{array}{l}-0.0007^{*} \\
(0.0003)\end{array}$ & $\begin{array}{l}-0.0007^{*} \\
(0.0003)\end{array}$ \\
\hline Gasoline price at a 18 -month lag & $\begin{array}{l}-0.0006^{\dagger} \\
(0.0003)\end{array}$ & $\begin{array}{c}-0.0004 \\
(0.0003)\end{array}$ & $\begin{array}{l}-0.0006^{*} \\
(0.0003)\end{array}$ & $\begin{array}{l}-0.0007^{*} \\
(0.0003)\end{array}$ & $\begin{array}{c}-0.0004 \\
(0.0003)\end{array}$ & $\begin{array}{l}-0.0006^{*} \\
(0.0003)\end{array}$ & $\begin{array}{c}-0.0005^{\dagger} \\
(0.0003)\end{array}$ \\
\hline Seat belt usage & $\begin{array}{l}-0.0186^{*} \\
(0.0076)\end{array}$ & $\begin{array}{l}0.01580^{\dagger} \\
(0.0090)\end{array}$ & $\begin{array}{l}-0.0195^{* *} \\
(0.0074)\end{array}$ & $\begin{array}{l}-0.0176^{*} \\
(0.0075)\end{array}$ & $\begin{array}{l}-0.0197^{*} \\
(0.0079)\end{array}$ & $\begin{array}{l}-0.0230^{* *} \\
(0.0076)\end{array}$ & $\begin{array}{l}-0.0099 \\
(0.0079)\end{array}$ \\
\hline State unemployment & $\begin{array}{l}0.0079 \\
(0.0153)\end{array}$ & $\begin{array}{l}-0.0056 \\
(0.0182)\end{array}$ & $\begin{array}{l}0.0127 \\
(0.0149)\end{array}$ & $\begin{array}{l}0.019 \\
(0.0151)\end{array}$ & $\begin{array}{l}-0.0048 \\
(0.0160)\end{array}$ & $\begin{array}{l}0.0065 \\
(0.0154)\end{array}$ & $\begin{array}{l}0.0109 \\
(0.016)\end{array}$ \\
\hline Alcohol sales & $\begin{array}{l}0.1247^{*} \\
(0.0609)\end{array}$ & $\begin{array}{l}0.1147 \\
(0.0724)\end{array}$ & $\begin{array}{l}0.1298^{*} \\
(0.0593)\end{array}$ & $\begin{array}{l}0.1602^{* *} \\
(0.06)\end{array}$ & $\begin{array}{l}0.0850 \\
(0.0637)\end{array}$ & $\begin{array}{l}0.1263^{*} \\
(0.0613)\end{array}$ & $\begin{array}{l}0.1223^{\dagger} \\
(0.0638)\end{array}$ \\
\hline Precipitation & $\begin{array}{l}0.0007 \\
(0.0041)\end{array}$ & $\begin{array}{l}0.0028 \\
(0.0048)\end{array}$ & $\begin{array}{l}4.62 \mathrm{E}-05 \\
(0.0040)\end{array}$ & $\begin{array}{l}0.0001 \\
(0.0040)\end{array}$ & $\begin{array}{l}0.0013 \\
(0.0043)\end{array}$ & $\begin{array}{l}0.0003 \\
(0.0041)\end{array}$ & $\begin{array}{l}0.0025 \\
(0.0043)\end{array}$ \\
\hline Temperature & $\begin{array}{l}-0.0020^{\dagger} \\
(0.001)\end{array}$ & $\begin{array}{l}-0.0015 \\
(0.0012)\end{array}$ & $\begin{array}{l}-0.0021^{*} \\
(0.0010)\end{array}$ & $\begin{array}{l}-0.0015 \\
(0.0010)\end{array}$ & $\begin{array}{l}-0.0026^{*} \\
(0.0011)\end{array}$ & $\begin{array}{l}-0.0019^{\dagger} \\
(0.0010)\end{array}$ & $\begin{array}{l}-0.0021^{*} \\
(0.0011)\end{array}$ \\
\hline Time trend & $\begin{array}{l}0.0052^{*} \\
(0.0024)\end{array}$ & $\begin{array}{l}0.0036 \\
(0.0029)\end{array}$ & $\begin{array}{l}0.0057^{*} \\
(0.0024)\end{array}$ & $\begin{array}{l}0.0037 \\
(0.0024)\end{array}$ & $\begin{array}{l}0.0068^{* *} \\
(0.0025)\end{array}$ & $\begin{array}{l}0.0069^{* *} \\
(0.0024)\end{array}$ & $\begin{array}{l}0.0018 \\
(0.0025)\end{array}$ \\
\hline Constant & $\begin{array}{l}-7.2213^{* * * *} \\
(1.9921)\end{array}$ & $\begin{array}{l}-6.7528^{* *} \\
(2.3665)\end{array}$ & $\begin{array}{l}-7.4240^{* * *} \\
(1.9381)\end{array}$ & $\begin{array}{l}-8.1624^{* * *} \\
(1.9607)\end{array}$ & $\begin{array}{l}-6.1635^{* *} \\
(2.0835)\end{array}$ & $\begin{array}{l}-6.9627^{\text {**** }} \\
(2.0038)\end{array}$ & $\begin{array}{l}-7.7029^{* * * *} \\
(2.0849)\end{array}$ \\
\hline $\begin{array}{l}\text { Pseudo } R^{2} \\
\text { Log likelihood }\end{array}$ & $\begin{array}{l}0.0488 \\
-653.6695\end{array}$ & $\begin{array}{l}0.0591 \\
-554.5863\end{array}$ & $\begin{array}{l}0.0486 \\
-628.4188\end{array}$ & $\begin{array}{l}0.0691 \\
-600.5204\end{array}$ & $\begin{array}{l}0.0373 \\
-596.7263\end{array}$ & $\begin{array}{l}0.0504 \\
-619.5972\end{array}$ & $\begin{array}{l}0.0539 \\
-571.8585\end{array}$ \\
\hline
\end{tabular}

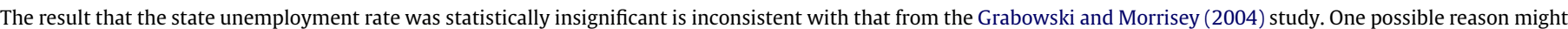

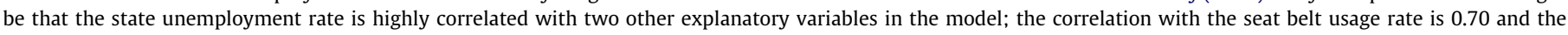
correlation with alcohol sales is -0.66 . The two explanatory variables are statistically significant in most of the models.

Notes: Standard errors in parentheses.

$\dagger \leqslant 0.10$.

${ }^{*} p \leqslant 0.05$.

*** $p \leqslant 0.01$.

*** $p \leqslant 0.001$.

Table B1

Negative binomial regression models for fatal crashes per capita in Mississippi, April 2004-December 2010.

\begin{tabular}{|c|c|c|c|c|c|c|c|}
\hline & \multirow[t]{2}{*}{ Total } & \multicolumn{2}{|l|}{ Age } & \multicolumn{2}{|l|}{ Gender } & \multicolumn{2}{|l|}{ Race } \\
\hline & & $15-23$ years & $24+$ years & Men & Women & White & Black \\
\hline Gasoline price at the current time & $\begin{array}{l}-0.0008 \\
(0.0006)\end{array}$ & $\begin{array}{l}-0.0018 \\
(0.0013)\end{array}$ & $\begin{array}{l}-0.0006 \\
(0.0006)\end{array}$ & $\begin{array}{l}-0.0007 \\
(0.0007)\end{array}$ & $\begin{array}{l}-0.0009 \\
(0.0009)\end{array}$ & $\begin{array}{l}-0.0005 \\
(0.0007)\end{array}$ & $\begin{array}{l}-0.0015^{\dagger} \\
(0.0008)\end{array}$ \\
\hline Gasoline price at a 9-month lag & $\begin{array}{l}-0.0001 \\
(0.0006)\end{array}$ & $\begin{array}{l}0.0012 \\
(0.0011)\end{array}$ & $\begin{array}{l}-0.0005 \\
(0.0006)\end{array}$ & $\begin{array}{l}-0.0007 \\
(0.0006)\end{array}$ & $\begin{array}{l}0.0014 \\
(0.0009)\end{array}$ & $\begin{array}{l}-0.0004 \\
(0.0007)\end{array}$ & $\begin{array}{l}-0.0003 \\
(0.0008)\end{array}$ \\
\hline Gasoline price at a 12-month lag & $\begin{array}{l}-0.0012 \\
(0.0007)\end{array}$ & $\begin{array}{l}-0.0014 \\
(0.0014)\end{array}$ & $\begin{array}{l}-0.0010 \\
(0.0007)\end{array}$ & $\begin{array}{l}-0.0006 \\
(0.0008)\end{array}$ & $\begin{array}{l}-0.0027^{*} \\
(0.0011)\end{array}$ & $\begin{array}{l}-0.0017^{*} \\
(0.0008)\end{array}$ & $\begin{array}{l}-0.0013 \\
(0.0010)\end{array}$ \\
\hline Gasoline price at a 18 -month lag & $\begin{array}{l}-0.0006 \\
(0.0007)\end{array}$ & $\begin{array}{l}0.0006 \\
(0.0013)\end{array}$ & $\begin{array}{l}-0.0009 \\
(0.0006)\end{array}$ & $\begin{array}{l}-0.0009 \\
(0.0007)\end{array}$ & $\begin{array}{l}0.0003 \\
(0.0009)\end{array}$ & $\begin{array}{l}-0.0009 \\
(0.0007)\end{array}$ & $\begin{array}{l}-0.0002 \\
(0.0009)\end{array}$ \\
\hline Seat belt usage & $\begin{array}{l}-0.0406^{*} \\
(0.0171)\end{array}$ & $\begin{array}{l}-0.0564^{\dagger} \\
(0.0308)\end{array}$ & $\begin{array}{l}-0.0358^{*} \\
(0.0161)\end{array}$ & $\begin{array}{l}-0.0351^{*} \\
(0.0176)\end{array}$ & $\begin{array}{l}-0.0556^{*} \\
(0.0244)\end{array}$ & $\begin{array}{l}-0.0419^{*} \\
(0.0183)\end{array}$ & $\begin{array}{l}-0.0534^{*} \\
(0.0218)\end{array}$ \\
\hline State unemployment & $\begin{array}{l}0.0067 \\
(0.0350)\end{array}$ & $\begin{array}{l}0.0121 \\
(0.0634)\end{array}$ & $\begin{array}{l}0.0068 \\
(0.0331)\end{array}$ & $\begin{array}{l}-0.0044 \\
(0.0363)\end{array}$ & $\begin{array}{l}0.0315 \\
(0.0497)\end{array}$ & $\begin{array}{l}-0.0032 \\
(0.0377)\end{array}$ & $\begin{array}{l}0.0192 \\
(0.0449)\end{array}$ \\
\hline Alcohol sales & $\begin{array}{l}0.2989^{*} \\
(0.1403)\end{array}$ & $\begin{array}{l}0.1895 \\
(0.2598)\end{array}$ & $\begin{array}{l}0.3383^{* *} \\
(0.1319)\end{array}$ & $\begin{array}{l}0.3163^{*} \\
(0.1477)\end{array}$ & $\begin{array}{l}0.2347 \\
(0.2016)\end{array}$ & $\begin{array}{l}0.3260^{*} \\
(0.1515)\end{array}$ & $\begin{array}{l}0.3304^{\dagger} \\
(0.1814)\end{array}$ \\
\hline Precipitation & $\begin{array}{l}-0.0140 \\
(0.0094)\end{array}$ & $\begin{array}{l}-0.0222 \\
(0.0177)\end{array}$ & $\begin{array}{l}-0.0131 \\
(0.0089)\end{array}$ & $\begin{array}{l}-0.0120 \\
(0.0098)\end{array}$ & $\begin{array}{l}-0.0207 \\
(0.0137)\end{array}$ & $\begin{array}{l}-0.0270^{* *} \\
(0.0104)\end{array}$ & $\begin{array}{l}-0.0164 \\
(0.0124)\end{array}$ \\
\hline Temperature & $\begin{array}{l}0.0019 \\
(0.0024)\end{array}$ & $\begin{array}{l}0.0085^{\dagger} \\
(0.0044)\end{array}$ & $\begin{array}{l}-0.0002 \\
(0.0022)\end{array}$ & $\begin{array}{l}0.0006 \\
(0.0025)\end{array}$ & $\begin{array}{l}0.0058^{\dagger} \\
(0.0034)\end{array}$ & $\begin{array}{l}0.0005 \\
(0.0026)\end{array}$ & $\begin{array}{l}0.0047 \\
(0.0031)\end{array}$ \\
\hline Time trend & $\begin{array}{l}0.0126^{*} \\
(0.0055)\end{array}$ & $\begin{array}{l}0.0061 \\
(0.01)\end{array}$ & $\begin{array}{l}0.0140^{* * *} \\
(0.0052)\end{array}$ & $\begin{array}{l}0.0119^{*} \\
(0.0057)\end{array}$ & $\begin{array}{l}0.0145^{\dagger} \\
(0.0078)\end{array}$ & $\begin{array}{l}0.0142^{*} \\
(0.0059)\end{array}$ & $\begin{array}{l}0.0130^{\dagger} \\
(0.0070)\end{array}$ \\
\hline Constant & $\begin{array}{l}-15.5986^{\text {**** }} \\
(4.5667)\end{array}$ & $\begin{array}{l}-11.9110 \\
(8.3850)\end{array}$ & $\begin{array}{l}-16.9108^{* * * *} \\
(4.2954)\end{array}$ & $\begin{array}{l}-15.7794^{* * *} \\
(4.7050)\end{array}$ & $\begin{array}{l}-14.1368^{*} \\
(6.5518)\end{array}$ & $\begin{array}{l}-16.0084^{* * *} \\
(4.9171)\end{array}$ & $\begin{array}{l}-15.8841^{* *} \\
(5.8789)\end{array}$ \\
\hline
\end{tabular}


Table B1 (continued)

\begin{tabular}{|c|c|c|c|c|c|c|c|}
\hline & \multirow[t]{2}{*}{ Total } & \multicolumn{2}{|l|}{ Age } & \multicolumn{2}{|l|}{ Gender } & \multicolumn{2}{|l|}{ Race } \\
\hline & & $15-23$ years & $24+$ years & Men & Women & White & Black \\
\hline Pseudo $R^{2}$ & 0.0674 & 0.0838 & 0.0742 & 0.0712 & 0.0523 & 0.0823 & 0.0827 \\
\hline Log likelihood & -328.5327 & -249.5226 & -305.6777 & -306.1121 & -252.0974 & -291.5179 & -253.8263 \\
\hline $\begin{array}{l}\text { Notes: Standard e } \\
{ }^{\dagger} p \leqslant 0.10 . \\
p \leqslant 0.05 . \\
{ }^{* * *} p \leqslant 0.01 \\
{ }_{* * * *} \\
p \leqslant 0.001 .\end{array}$ & & & & & & & \\
\hline
\end{tabular}

safety may be better explained by socioeconomic status than demographic characteristics. Future research could divide the crashes by the socioeconomic status of the drivers and examine their corresponding relationships with gasoline prices.

\section{Acknowledgments}

The authors would like to thank Neal Feierabend, Sheena Gardner, and Lee Weiskopf for deriving traffic crash data as well as Arthur Huang, David Parrish, Ron Sennett, and Randy Ginn for assistance in providing other data for this study. Appreciation is extended to David Keeling and Andrew Goetz, the Editors, and three anonymous reviewers for their many helpful comments. This research was supported by a grant from National Highway Traffic Safety Administration and Mississippi Office of Public Safety (Award Number 11 K9 401-1).

\section{Appendix A}

See Table A1.

\section{Appendix B}

See Table B1.

\section{References}

Beer Institute, 2011. Annual statistical abstracts of brewers Almanac. <http:// www.beerinstitute.org/statistics.asp?bid=200> (accessed 21.09.11).

Burns, L.D., 1979. Transportation, temporal, and spatial components of accessibility. Lexington Books, Lexington, MA.

Chi, G., Cosby, A., Quddus, M., Gilbert, P., Levinson, D., 2010. Gasoline prices and traffic safety in Mississippi. Journal of Safety Research 41 (6), 493-500.

Chi, G., Zhou, X., McClure, T., Gilbert, P., Cosby, A., Zhang, L., Robertson, A., Levinson, D., 2011. Gasoline prices and their relationship to drunk-driving crashes. Accident Analysis and Prevention 43 (1), 194-203.

Chi, G., McClure, T., Brown, D., 2012. Gasoline prices and traffic crashes in Alabama, 1999-2009. Traffic Injury Prevention 13 (5), 476-484.

Cullen, I., Godson, V., 1975. Urban networks: the structure of activity patterns. Progress in Planning 4 (1), 1-96.

Dahl, C., Sterner, T., 1991. Analyzing gasoline demand elasticities: a survey. Energy Economics 13 (3), 203-210.

Deka, D., 2004. Social and environmental justice issues in urban transportation. In: Hanson, S., Giuliano, G. (Eds.), The geography of urban transportation. The Guilford Press, New York, pp. 332-355.

Energy Information Agency, US Department of Energy, 2012. Gasoline and diesel fuel update. <http://www.eia.gov/dnav/pet/pet_pri_gnd_dcus_r30_w.htm> (accessed 30.08.12).

Evan, W., Graham, J., 1991. Risk reduction or risk compensation? The case of mandatory safety-belt use laws. Journal of Risk and Uncertainty 4 (1), 61-73.

Goodwin, P., Dargay, J., Hanly, M., 2004. Elasticities of road traffic and fuel consumption with respect to price and income: a review. Transport Reviews 24 (3), 275-292.

Grabowski, D., Morrisey, M., 2004. Gasoline prices and motor vehicle fatalities. Journal of Policy Analysis and Management 23 (3), 575-593.

Graham, D., Glaister, S., 2003. Spatial variation in road pedestrian casualties: the role of urban scale, density and land-use mix. Urban Studies 40 (8), 1591-1607.

Graham, D., Glaister, S., 2004. Road traffic demand elasticity estimates: a review. Transport Reviews 24 (3), 261-274.
Hägerstrand, T., 1970. What about people in regional science? Papers in Regional Science 24 (1), 1-12.

Horner, R., Day, G., Lanier, A., Provost, E., Hamel, R., Trimble, B., 2009. Stroke mortality among Alaska native people. American Journal of Public Health 99 (11), 1-5.

Huang, A., Levinson, D., 2010. The effects of daylight saving time on vehicle crashes in Minnesota. Journal of Safety Research 41 (6), 513-520.

Kitamura, R., Fujii, S., 1996. Two computational process models of activity-travel behavior. In: Paper Presented at the Theoretical Foundations of Travel Choice Modeling Conference, Stockholm, Sweden, 7-11 August 1996.

Kwan, M., 1998. Space-time and integral measures of individual accessibility: a comparative analysis using a point-based network. Geographical Analysis 30 (3), 191-216.

Lane, B., 2010. The relationship between recent fuel price fluctuations and transit usage in major US cities. Journal of Transport Geography 18 (2), 214-225.

Leigh, J., Geraghty, E., 2008. High gasoline prices and mortality from motor vehicle crashes and air pollution. Journal of Occupational and Environmental Medicine 50 (3), 249-254.

Leigh, J., Wilkinson, J., 1991. The effect of gasoline taxes on highway fatalities. Journal of Policy Analysis and Management 10 (3), 474-481.

Lenntorp, B., 1976. Paths in time-space environments: a time geographic study of movement possibilities of individuals. Lund Studies in Geography, vol. 44. Royal University of Lund, Sweden.

Long, J.S., 1997. Regression models for categorical and limited dependent variables. Sage Publications, Thousand Oaks, CA.

Massey, D., Denton, N., 1993. American apartheid: segregation and the making of the underclass. Harvard University Press, Cambridge, MA.

McGuckin, N., Nakamoto, Y., 2006. Differences in trip chaining by men and women. In: Research on Women's Issues in Transportation, vol. 1. Chicago, IL 18-20 November 2004. Transportation Research Board, Washington, DC, pp. 49-56.

Meyer, M., 2006. Women's issues in transportation: policy and planning. In: Research on Women's Issues in Transportation, vol. 1. Chicago, IL 18-20 November 2004. Transportation Research Board, Washington, DC, pp. 5158.

Miller, H., 1991. Modelling accessibility using space-time prism concepts within geographical information systems. International Journal of Geographical Information Systems 5 (3), 287-301.

Miller, H., Bridwell, S., 2009. A field-based theory for time geography. Annals of the Association of American Geographers 99, 49-75.

Mississippi Department of Public Safety, 2010. Seat Belt and Motorcycle Helmet Survey. <http://psdl.ssrc.msstate.edu/reports/seatbelt/Reports/2010_Seatbelt_ Report.pdf $>$ (accessed 21.09.11).

Pred, A., 1977. The choreography of existence. Comments on Hägerstrand's timegeography and its usefulness. Economic Geography 53 (2), 207-221.

Quddus, M., 2008. Modelling area-wide count outcomes with spatial correlation and heterogeneity: an analysis of London crash data. Accident Analysis and Prevention 40 (4), 1486-1497.

Raphael, S., Stoll, M., 2001. Can boosting minority car-ownership rates narrow interracial employment gaps? In: Gale, W.G., Pack, J.R. (Eds.), The BrookingsWharton Papers on Urban Economic Affairs, vol. 2. The Brookings Institution, Washington, DC, pp. 99-145.

Ren, F., Kwan, M., 2009. The impact of the internet on human activity-travel patterns: analysis of gender differences using multi-group structural equation models. Journal of Transport Geography 17 (6), 440-450.

Shaw, S., Yu, H., 2009. A GIS-based time-geographic approach of studying individual activities and interactions in a hybrid physical-virtual space. Journal of Transport Geography 17 (2), 141-149.

Southeast Regional Climate Center, 2012. Monthly Statewide Precipitation and Temperature Averages, 1895-2012. <http://www.sercc.com/climateinfo/ monthly_seasonal.html> (accessed 06.04.12).

US Bureau of Census, 2011. Quick Facts. <http:/quickfacts.census.gov/qfd/states/ 28000.html> (accessed 21.09.11).

US Bureau of Labor Statistics, 2011. Local Area Unemployment Statistics. <http:// data.bls.gov/pdq/SurveyOutputServlet> (accessed 21.09.11).

van den Bossche, F., Wets, G., Brijs, T., 2007. Analysis of road risk per age and gender category: time series approach. Transportation Research Record: Journal of the Transportation Research Board 2019, 7-14. 
Wilson, F., Stimpson, J., Hilsenrath, P., 2009. Gasoline prices and their relationship to rising motorcycle fatalities, 1990-2007. American Journal of Public Health 99 (10), 1753-1758.

Woodcock, A., Lenard, J., Welsh, R., 2001. The safety and security issues of women drivers and passengers. World Transport Policy and Practice 7 (1), 15-21.
Yu, H., Shaw, S., 2007. Revisiting Hägerstrand's time-geographic framework for individual activities in the age of instant access. In: Miller, H.J. (Ed.), Societies and Cities in the Age of Instant Access. Springer, Dordrecht, The Netherlands, pp. 103-118. 